\title{
Building an eco-effective district heating management system in a city
}

\author{
Leonid Gitelman ${ }^{1}$, Elena Magaril ${ }^{1}$, Mikhail Kozhevnikov ${ }^{1 \mathrm{a}}$, Giuseppe Genon ${ }^{2}$, AnnaMaria \\ Senor $^{2}$, and Debora Panepinto ${ }^{2}$ \\ ${ }^{1}$ Research and Educational Centre ENGEC, Ural Federal University, 620002, Yekaterinburg, Russia \\ ${ }^{2}$ Turin Polytechnic, 10129, Torino, Italy
}

\begin{abstract}
The goal of making the urban environment safer amid increasing human impact adds to the importance of district heating management. The article outlines the results of a study into the problem of improving the urban environment by implementing two innovative solutions. Technological innovations imply the introduction of modern sustainable tools of reducing emissions in district heating networks, one of them being the combination of district heating and combined heat and power plants (a case study of Turin). Organizational innovations are built upon the management of demand for thermal energy that makes it possible to reduce investment in new construction and to optimize the architecture of heat load schedules for the purpose of alleviating energy and environmental pressure on the city. The authors propose formats and areas of demand side management for thermal energy and methods of offering economic incentives to program participants.
\end{abstract}

\section{Introduction}

District heating networks in cities are characterized by inertia as regards their development, which is due to numerous factors affecting their relative competitive edge, such as the duration of the heating season, heat loads, growth in single-family construction; the structure of consumers. This is the reason why in different towns the share of consumers connected to district heating networks may vary greatly.

In developing countries, such as Russia, district heating networks are characterized by low economic efficiency and environmental effectiveness, primarily because of outdated and worn-out installations. Overhauling them would require huge investment. There is also a lack of interest from investors because of rigid tariff policies of governments and regulators.

In many countries, especially in big cities, heating is supplied by numerous organizations of various affiliations and ownership status (private, municipal, state-owned ones). At the same time, a unified integrated system for heat supply management in the city as a whole is practically non-existent. Such a system would coordinate the operation of these organizations and direct them towards meeting public interests, and create

\footnotetext{
${ }^{\text {a }}$ Corresponding author: np.fre@,mail.ru
} 
a competitive environment that would take into account the specific features of heating supply.

The context brings to the forefront the issue of municipal combined heat and power (CHP) plants. CHP plants have to simultaneously operate in electricity and heat markets that differ greatly in terms of their size, competition and demand. The efficiency of CHP plants during electricity generation is strongly dependent on heat loads, i.e., it is seasonal. Consequently, the ability of CHP plants to compete in the wholesale electricity market is objectively a variable. It is not ruled out though, that the generating capacity of some CHP plants will not be needed by the electricity market. The plants may turn into district boilers as a result, thus discrediting the idea of district heating in the long-term perspective.

The results of the study described by the authors focus on two elements of a heat supply management mechanism proposed by the authors. The mechanism includes economic, administrative and legal tools for serving the interest of major participants in the heat market, with the elements in focus being the improvement of environmental effectiveness and building a demand-side management system.

\section{A study of environmental issues of heat supply in a city}

An environmental analysis of the development of district heating (DH) was performed using the case of the DH system built in Turin (Piedmont, North Italy) and the forecast project of its expansion for the next eight years [1]. Technological solutions that are employed in the Turin DH system make it a highly interesting case to study in particular because they place the city at the core of the widest district heating network of Italy, which is also one of the most expansive DH systems in Europe. The system of combined heat and power production in Turin has proven its high efficiency in terms of energy savings, and makes it possible to minimize the environmental impact by integrating cogeneration into DH systems. The evaluation of the compatibility of the existing Turin plant configurations connected with DH may prove useful as a decision-making tool for policy-makers.

The research programme included the following steps.

1. Examination of social and economic factors that can potential become an obstacle to the development of district heating.

2. Building the energy and environmental balance of the city.

3. Evaluation of pollutant emissions $\left(\mathrm{SO}_{2}, \mathrm{NO}_{\mathrm{x}}, \mathrm{PM}_{10}, \mathrm{CO}_{2}\right)$ in cogeneration mode.

4. Building 3D models of pollutant dispersion.

5. Identifying the areas of the city with critically high concentrations of pollutants.

6. Optimization of the deployment of thermal power plants in the territory of study [2-5].

To define the dispersion and transport of pollutants, the AERMOD model was used, which is an evolution of the Gaussian model ISC3. The model was developed by the American Meteorological Society (AMS) for the Environmental Protection Agency (EPA). In order to establish ground level concentrations within an area of $40 \times 40 \mathrm{~km}$ (Figure 1), the following methodology was used. First of all, a set of maps of ground-level concentrations following the activation of cogeneration units and their enlargement/reservation was formed. Then, for each zone of the district heating usage (domestic boilers) barycentric stacks were set. Finally, the result was obtained as the calculated difference between the added and the prevented (thanks to the replacement of thermal power plants) emissions.

The analysis leads to a number of conclusions:

- it was possible to establish the environmental compatibility of the CHP plants by assessing the possibility of ensuring significantly lower concentration values than allowed limits;

- information that is yielded by the emissive environmental balance is definitive only for $\mathrm{CO}_{2}$ 
- the ground-level concentration maps establish a fundamental baseline for the local analysis in the form of the mean annual values in the nearest municipalities.

In general, the obtained results highlight a sharp drop in the soil concentrations of nitrogen oxides and dust (PM10) that encourage the extension of the DH Scenario in place in Turin (Figure 2). On a global scale, net $\mathrm{CO}_{2}$ reductions open up a path for the reduction of climate-altering emissions, as shown in Figure 3.

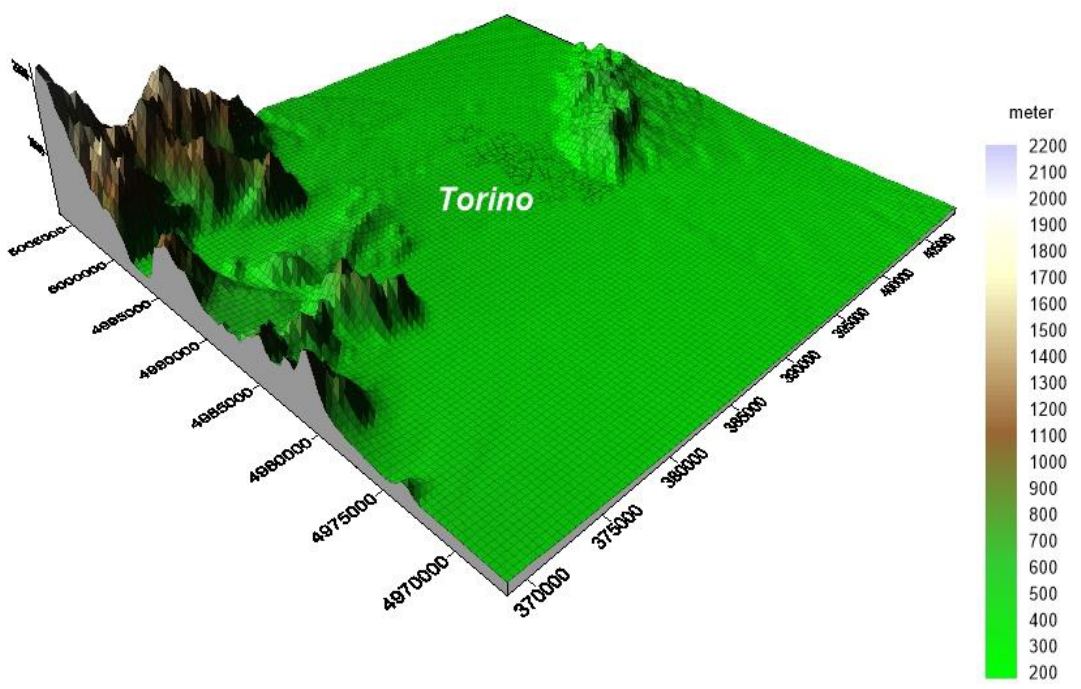

Fig. 1. Study Area.

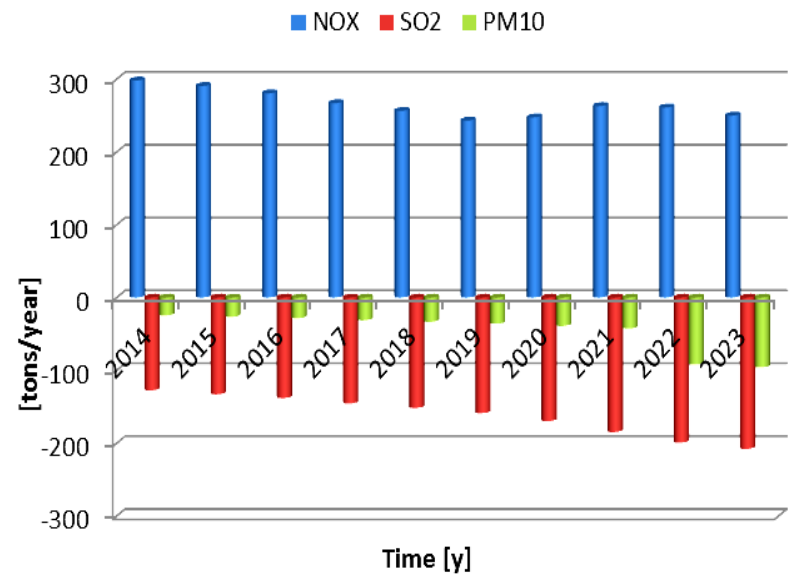

Fig. 2. Pollutant Local Balance. 


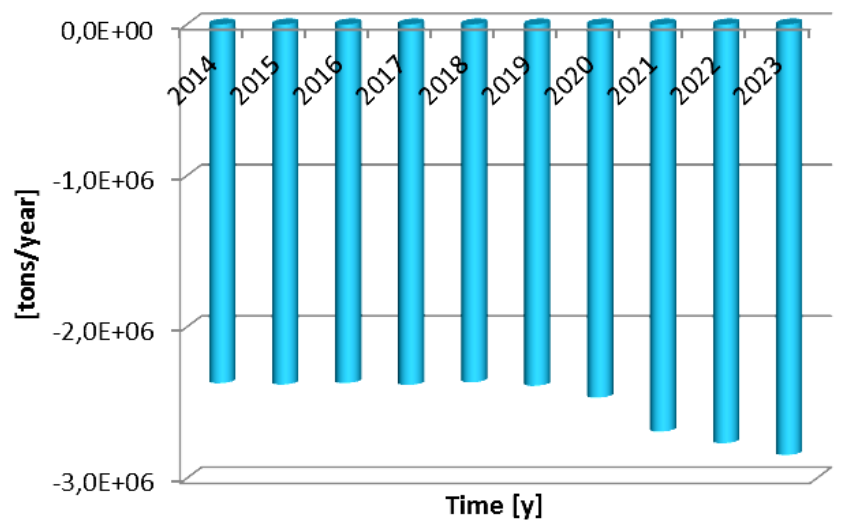

Fig. 3. $\mathrm{CO}_{2}$ Global Balance.

\section{Heat demand management}

Thermal energy demand management targets end consumers (manufacturing companies, non-manufacturing organizations, population and others), specific energy consuming processes (technological, heating and cooling loads, hot water supply), various energy carriers (hot water and steam at temperatures and pressure). Within the framework of demand side management, the authors consider the following tasks:

- streamlining the operation schedule of CHP plants by combining an increase in power generation from waste heat and utilizing the flexibility potential of CHP plants during minimum daily and seasonal loads;

- reducing operating and capital costs thanks to the lower cost of recovered heat vs. the cost of heat generated by new installations, higher efficiency of CHP equipment and boilers and a reduction in energy losses in distribution networks and consumer units;

- improving the competitive edge of energy companies in heat markets through lower tariffs, a wider range of energy efficiency services and improved reliability of electricity supply (for example, by discouraging consumers from building their own heat generators);

- the elaboration of more substantiated plans for putting into service new generation capacity at CHP plants and boilers with lower investment risk;

- accelerated decommissioning of inefficient and eco-destructive energy installations;

- a radical improvement of business relations with customers, municipal and regional authorities by seeking a more effective alignment of commercial and public interests of all parties involved.

There is a number of formats and areas of heat demand management that could be proposed as a solution to the above tasks.

1. Energy conservation. It covers all categories of consumers and is implemented in an number of ways such as building, pipe and equipment insulation, installation of metering devices and heating controllers at homes, a wider use of renewable energy sources and installation of different energy conservation equipment at production companies, improved efficiency of heat consuming equipment and the use of advanced energy conservation technologies.

2. Rational energy consumption scheduling. It is aimed at smoothing out daily and seasonal load curves in industry (load management). It can take the following forms: peak reduction, valley filling, load shifting. It includes such organizational and technical 
measures as shutting down equipment or load shedding during certain periods, a change in maintenance schedules, installation of standalone peak heat generators, steam accumulators etc.

3. Substitution of energy carriers. In principle, it is possible to substitute electric power for steam in some power-operated processes in production companies, and electric power for hot water in heating installations in the housing sector. It has to be emphasized that using CHP storage systems for heating purposes is not only a way to save thermal energy in the form of hot water, but also an effective way of filling the nighttime valley in the daily load curve. Heat demand management is, therefore, closely connected with electrification and electricity demand management [6]. There is an ensuing problem of striking a balance between the development of CHP units and separate heat and power production (steam-electric power stations and boilers). Obviously, as electricity consumption keeps growing, the share of CHP plants with low steam parameters and turbines with condensers will gradually go down because their operation in condensing mode is highly inefficient.

In low and medium temperature processes steam and hot water are also two competing energy carriers. Hot water can successfully replace steam not only for heating purposes, but also in some technological industrial process that use low-temperature heat..

4. Reducing the parameters of energy carriers. It acceptable to lower the pressure and temperature of process steam as well as of the temperature of hot water used for technological processes, heating and hot water supply in industrial facilities and community buildings, provided this does not disrupt production processes or affect the quality of products and minimum indoor thermal comfort. For example, water temperature in the heating systems of shopfloors could be lowered during working hours considering the heat output of equipment. For companies and organizations operating one and two shifts a day the air temperature could also be lowered significantly during night hours. Naturally, none of this is applicable to the housing sector.

Methods of providing economic incentives to DSM program participants are selected with regard to the specific features of the program, first and foremost the goals and subjects of demand side management. In the general case, the following system of methods and economic incentives could be considered.

1. Various ways of distributing cost savings in combined cycle generation (at CHP plants) between electric and thermal energy: those reducing the cost of electricity production; those reducing the cost of thermal energy, and those reducing the cost of thermal energy and electricity in comparison with separate heat and power production (a compromise solution).

The selection of a specific option is driven by the goals of incentives, such as substituting electric power for steam and hot water or increasing the competitive ability of an energy company in the heat market.

2. Tariffs for thermal energy that are differentiated by the energy carrier and its parameters (steam at various pressure levels, hot water), the type of the energy consuming process (technology, heating, hot water supply), time of consumption (time of the day, day of the week, season), and by the amount consumed.

To use tariffs as incentives, it is acceptable to allow them to differ from the actual cost of service (cost of energy supply). For example, in order to encourage energy conservation tariffs grow along with an increase in energy consumption (so-called progressive tariff). Special discounts and extra charges are applied to tariffs for competing energy carriers.

3. A one-time charge for connecting consumers to heating networks of the energy company, with its size being differentiated with regard to energy efficiency characteristics 
of buildings to be connected. In this case additional revenue from the least efficient consumers will be used to fund discounts for the most efficient consumers.

4. Discounted tariffs for thermal energy for consumers who agree to intermittent restrictions on heat loads and the lowering of energy carrier parameters. A multi rate tariff with a separate charge for the connected heat capacity of the consumer seems to be the most appropriate option for this method. In this case, discounts are offered on the capacity fee (or the maximum declared load). Additionally, discounts can be offered on the price of energy efficient equipment, direct investment and targeted monetary loans for consumers.

\section{Conclusion}

When building a "green" district heating system in a city, a number of factors must be taken into account:

- technical characteristics of the existing systems (configuration, capacity, regulatory capabilities) and the structure of thermal energy generating capacity;

- the baseline level of reliability and quality of heat supply (deterioration, per unit cost of fuel, energy loss in mains and distribution networks, repair and maintenance costs);

- ground level pollutant concentrations in heating delivery areas;

- the structure of consumers that determines appropriate calculation methods and nonpayment risk;

- the preparedness of municipalities to introduce the newest organization mechanisms of heat demand management and cooperation with energy companies and consumers.

It should be noted that it is increasingly important for energy companies to become proactive in creating demand rather than responding to it amid uncertainty about energy consumption, intensifying investment risk and stronger competition in energy markets and in heat markets in particular.

\section{Acknowledgement}

This research was supported by Act 211 Government of the Russian Federation, contract № 02.A03.21.0006.

\section{References}

1. A. Poggio, C. Maga, P. Benedetti, Provincia di Torino. Piano di sviluppo del teleriscaldamento nell 'area di Torino, Rapporto finale (Tecnoapi, Torino, 2009)

2. A. Senor, D. Panepinto, G. Genon, WIT Trans. Built Env., 168, 651-662 (2015)

3. M.F. Torchio, G. Genon, A. Poggio, M. Poggio, Energy, 34 (3), 220-227 (2009)

4. G. Genon, M.F. Torchio, A. Poggio, M. Poggio, Energ. Convers. Manage., 50 (3), $522-$ 529 (2009)

5. D. Panepinto, A. Senor, G. Genon, WIT Trans. Ecol. Envir., 180, 479-490 (2014)

6. L.D. Gitelman, B.E. Ratnikov, M.V. Kozhevnikov, Economy of Region, 2, 78-84, (2013) 